MATEC Web of Conferences 22,04002 (2015)

DOI: $10.1051 /$ matecconf/ 20152204002

(C) Owned by the authors, published by EDP Sciences, 2015

\title{
Research on the Mechanical Properties of Frame Structure Staircase Set- ting Isolation Bearing
}

\author{
Xiao Liu \& Liang Bai \\ School of Civil Engineering, Chang'an University, Xi'an, Shaanxi, China \\ Li Xin \\ China Northwest Architectural Design and Research Institute, Xi'an, Shaanxi, China
}

\begin{abstract}
First, in order to make the stair be a life channel in the earthquake, the authors set an isolation bearing between the platform beam and stair plate to separate the main structure and the stair. It can avoid the adverse effects on the main structure under the earthquake. Then this paper designs three reinforced concrete frame models: one including stairs, one excluding stairs and one including the stairs with the use of isolation measures. And the authors use the response spectrum method for each model to calculate and analyze, the results show that the staircase had an impact on the lateral stiffness of the structure, and the seismic performance had an obvious difference between the model including stairs and the model excluding stairs. The layout of stairs can change the structure stiffness center, thus affect the torsion effects of the structure. The stairs, the staircase frame column force and the sway were increased and formed the weak parts of force. By setting the isolator to separate stairs with the main structure, the stairwell structural damping ratio is increased, the seismic effects on stair components are effectively reduced, the staircase column internal forces are significantly reduced and they can avoid the staircase column damage occurred under an earthquake. At last, this paper presents a reasonable measure to separate stairs from the overall structure, and a design and calculation method to set isolator in the frame structure staircase. It can make stairs members do not participate in seismic calculations of the overall structure and can effectively avoid the stairs component damage.
\end{abstract}

Keywords: frame structure; stair; isolation bearing; seismic performance; design method

\section{INTRODUCTION}

In the traditional design of the stairs, structural engineers lack attention to the seismic design of the staircase, when the calculation of the structural models of staircase is often left out. They neither take the seismic performance of staircase components into account, nor consider the influence of staircase components on the seismic behavior of the structure. However, in the Wenchuan earthquake, the survey found that staircases of the structure (especially the frames) are damaged seriously. The stairs are a part of the structure, which are bound to influence the dynamic performance of the structure. At the same time, the changes of the structure's dynamic performance will inevitably affect the safety of the stairs. Therefore, doing research without consideration of the influence of stairs when analyzing may lead to the whole structure and the staircase (inter) which are badly damaged during the earthquake.

In the serious earthquake, the staircase is the only channel to escape so the stream of people will be the biggest immediately. If the staircase structure ware is severely damaged or the staircase structure damage which caused damages to non-structural components and made the escape channel interrupted or blocked then they will lead to serious consequences. Therefore, the staircase design is the design of lifeline; the stairs should be designed as the "safety island" of the whole structure.

This paper uses the finite element analysis software ETABS to build three reinforced concrete frame models, the first one including the staircase and the second does not have the staircase and the last one uses isolation measures. Then, analyze the three models by the response spectrum method. At last, this paper puts forward a kind of reasonable design method of isolation bearing that will make the stairs separate from the structure.

\section{ESTABLISHMENT OF CALCULATION MOD-} EL

In this paper, there are three reinforced concrete frame models in total.

Model 1 (M-1) is a seven-story reinforced concrete frame structure, the height of the first floor is $3.5 \mathrm{~m}$ and the rest are $3 \mathrm{~m}$. Grid size is $6.0 \mathrm{~m} * 6.0 \mathrm{~m}$. There are three crosses in each X-direction and Y-direction. The Frame column section sizes are $600 \mathrm{~mm} * 600 \mathrm{~mm}$ and $500 \mathrm{~mm} * 500 \mathrm{~mm}$ and the concrete strength grade is C35.The structure only have main frame beams whose section size is $300 \mathrm{~mm} * 600 \mathrm{~mm}$ and the con- 


\section{MATEC Web of Conferences}

crete strength grade is C30. The floor's concrete strength grade is C30 and its thickness is $120 \mathrm{~mm}$. This model has no stairs

Model 2 (M-2) is established on the basis of M-1 and set stairs in accordance with the actual situation. The rest platform's thickness is $120 \mathrm{~mm}$; the ladder's thickness is $120 \mathrm{~mm}$; the staircase column section size is $300 \mathrm{~mm} * 300 \mathrm{~mm}$; the size of beam section is $250 \mathrm{~mm}$ * $400 \mathrm{~mm}$; the concrete strength grade is C30.

Model 3 (M-3) is built on the basis of M-2 and the isolation bearings are arranged between the stairs and platform's beams.

In this analysis, the floor slabs are simulated by the membrane element; the stair slabs are simulated by the shell element; beams and columns are simulated by the space bar element model; and the freedoms of each model bottom are fixed in the analysis. The model's planes and graphic models are shown in Figure 1.

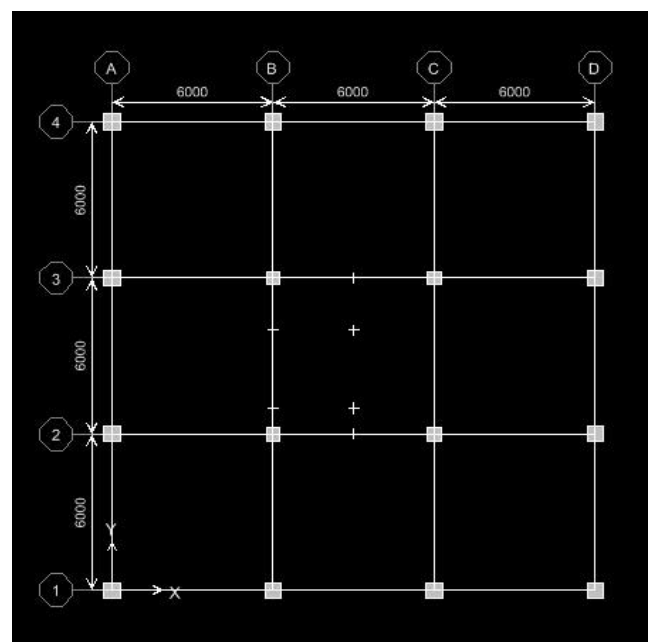

(a) Plane graph of the structure

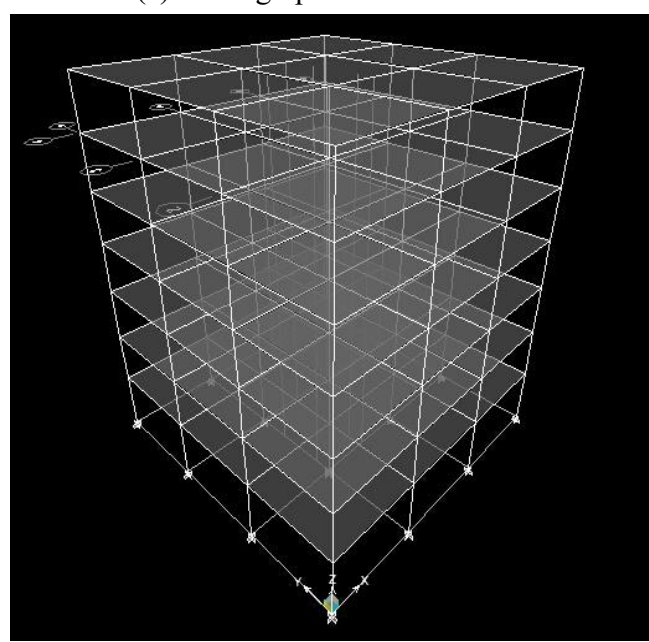

(b) Graphic model of M-1

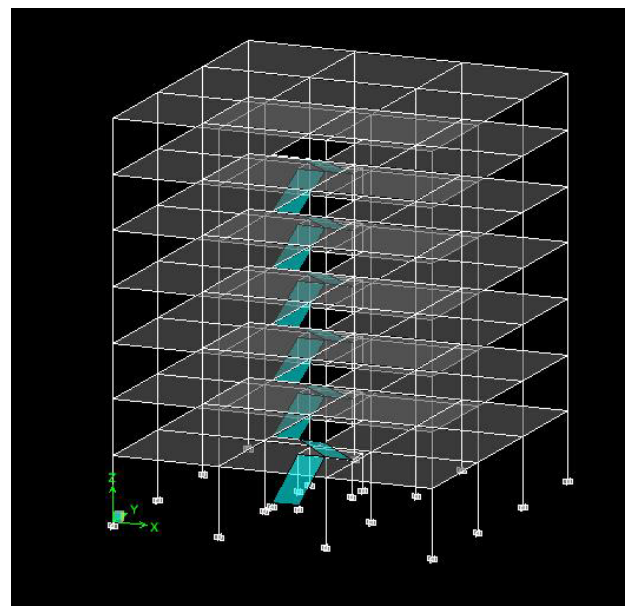

(c) Graphic model of M-2

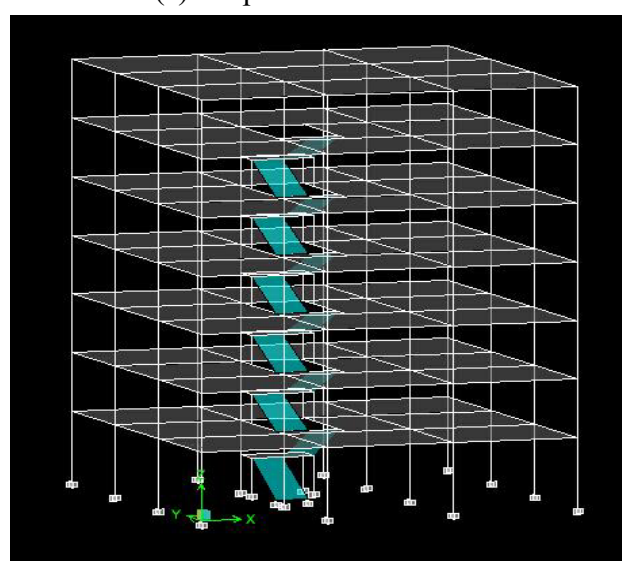

(d) Graphic model of M-3

Figure 1. Details of computer models

\section{ASSUMPTIONS IN THE CALCULATION}

Assume that the Seismic fortification intensity is 8 $(0.2 \mathrm{~g})$, the classification of design earthquake is one group which is the Site Classification II ( $\mathrm{T}=0.35 \mathrm{~s})$ the floor's additional dead load is $2.5 \mathrm{KN} / \mathrm{m}^{2}$ and the live load is $2 \mathrm{KN} / \mathrm{m}^{2}$. Then, use the mode-decomposition response spectrum method to analyze the models. Floors are assumed infinitely rigid in its own plane.

\section{ANALYSIS OF THE CALCULATION RESULTS}

4.1 Analysis of the response spectrum method's calculation results

Modal analysis uses the Ritz vector method to consider the effects of dynamic loads on the dynamic performance of the structure. The mode number of calculation is 12 and the result shows that the modal participation mass is more than $90 \%$ of the total weight. The 
structural damping is 0.05 , the response spectrum is chosen in the "seismic design code", and the modal combination and the direction combination respectively use the CQC method and the modified SRSS method.

(1) The vibration periods and the modal participation ratios of the front 5 modes of participation coefficient are shown in Table 1 to Table 3 .

Table1. Period and mass-ratios of mode $(1 \sim 5)$ of M-1

\begin{tabular}{lllll}
\hline Mode of vibration & $\mathrm{T} / \mathrm{s}$ & $U_{x}$ & $U_{y}$ & $R_{z}$ \\
\hline Mode-1 & 1.05423 & 31.29 & 51.35 & 0 \\
Mode-2 & 1.05423 & 51.35 & 31.29 & 0 \\
Mode-3 & 0.33006 & 3.26 & 6.94 & 0 \\
Mode-4 & 0.33006 & 6.94 & 3.26 & 0 \\
Mode-5 & 0.17889 & 1.49 & 2.38 & 0 \\
\hline
\end{tabular}

Table 2. Period and mass-ratios of mode $(1 \sim 5)$ of $\mathrm{M}-2$

\begin{tabular}{lllll}
\hline Mode of vibration & $\mathrm{T} / \mathrm{s}$ & $U_{x}$ & $U_{y}$ & $R_{z}$ \\
\hline Mode-1 & 1.00232 & 0.82 & 3.14 & 78.81 \\
Mode-2 & 0.9634 & 81.36 & 0.47 & 0.62 \\
Mode-3 & 0.8457 & 0.26 & 78.83 & 3.33 \\
Mode-4 & 0.31491 & 0.17 & 0.4 & 9.41 \\
Mode-5 & 0.30745 & 9.97 & 0.05 & 0.13 \\
\hline
\end{tabular}

Table 3. Period and mass-ratios of mode $(1 \sim 5)$ of M-3

\begin{tabular}{lllll}
\hline Mode of vibration & $\mathrm{T} / \mathrm{s}$ & $U_{x}$ & $U_{y}$ & $R_{z}$ \\
\hline Mode-1 & 1.01142 & 30.26 & 3.39 & 49.17 \\
Mode-2 & 0.99527 & 1.76 & 6.37 & 24.74 \\
Mode-3 & 0.96942 & 0.89 & 73.17 & 8.86 \\
Mode-4 & 0.3183 & 7.97 & 0.17 & 1.88 \\
Mode-5 & 0.31402 & 1.93 & 2.33 & 5.73 \\
\hline
\end{tabular}

By contrasting Table 1, Table 2 and Table 3, we can see that: 1) the modes of model 1 are all translations in $\mathrm{X}$-direction and $\mathrm{Y}$-direction and illustrate that the model is symmetrical and the structural torsion is not obvious; in model 2, the first mode is twisting around $\mathrm{Z}$-axis, the second mode is a translation in $\mathrm{X}$-direction, the third mode is a translation in Y-direction;in model 3 , the first mode is twisting around $\mathrm{Z}$-axis and a translation in $X$-direction (It is primary to be twisting around $\mathrm{Z}$-axis), the second mode is a translation in $\mathrm{X}$-direction, which is twisting around $\mathrm{Z}$-axis (It is primary to be a translation in X-direction), the third mode is a translation in Y-direction. 2) The first translational vibration period of model 2 is significantly less than that of model 1 and model 3, reduced to $80.2 \%$ and $87.2 \%$ in the Y-direction which is parallel with the boards of the ladder and reduced to $91.4 \%$ and $96.8 \%$ in the Y-direction.

(2) The floor displacement, the storey drifts, the floor shear and the floor rigidity of models in $\mathrm{X}$-direction are shown in Figure 2. The maximum values of them are shown in Table 4.

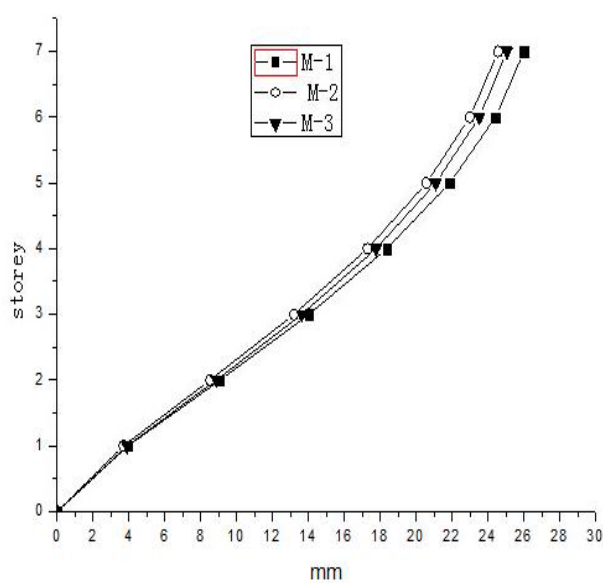

(a) Floor displacement curve

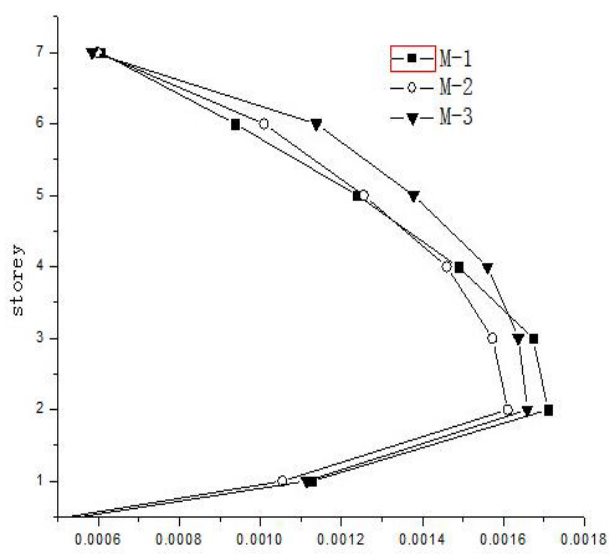

(b) Storey drift curve

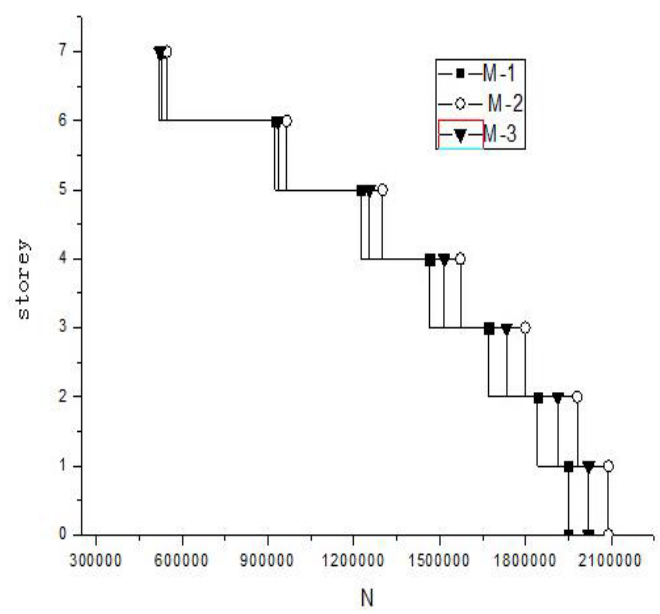

(c) Floor shear curve 


\section{MATEC Web of Conferences}

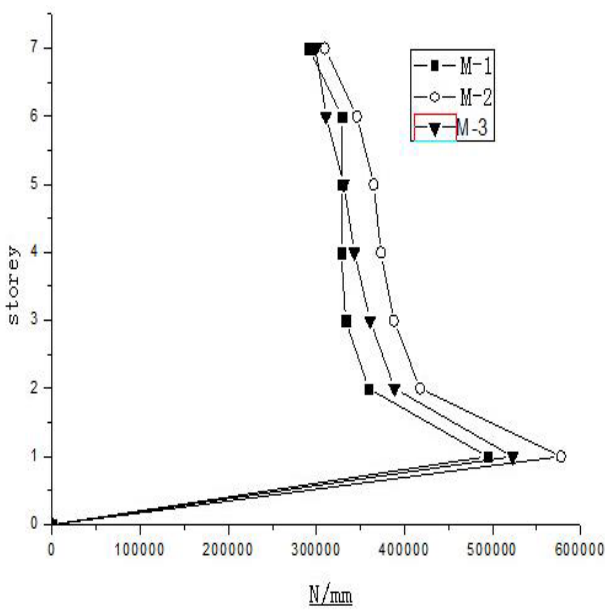

(d) Floor rigidity curve

Figure 2. Storey displacement, storey drifts, storey force and storey stiffness of models in X-direction

Table 4. Maximum of storey response based on spectrum-case of model (X-direction)

\begin{tabular}{lllll}
\hline Model & $\begin{array}{l}\text { Floor displace- } \\
\text { ment }(\mathrm{mm})\end{array}$ & $\begin{array}{l}\text { Storey } \\
\text { drifts }\end{array}$ & $\begin{array}{l}\text { Floor shear } \\
(\mathrm{kn})\end{array}$ & $\begin{array}{l}\text { Floor rigid- } \\
\text { ity }(\mathrm{kn} / \mathrm{mm})\end{array}$ \\
\hline M-1 & 25.9957 & $1 / 585$ & 1949 & 494 \\
M-2 & 24.5631 & $1 / 621$ & 2090 & 577.6 \\
M-3 & 25.0471 & $1 / 603$ & 2021 & 522.7 \\
\hline
\end{tabular}

Figure 2 and Table 4 show: 1) the floor displacement of model 1 is less than the floor displacement of model 2, the floor displacement of model 3 is between the floor displacement model 1 and model 2. 2) The maximum storey drifts of the three models are all at the second storey; the maximum storey drifts of model 2 is $5.8 \%$ less than the max storey drifts of model 1 ; the maximum storey drifts of model 3 is $3 \%$ less than the maximum storey drifts of model 1.3) The maximum floor shear of model 2 is $7.2 \%$ more than the maximum floor shear of model 1; the maximum floor shear of model 3 is $3.7 \%$ more than the maximum floor shear of model 1.4) The maximum floor rigidity of model 2 is $16.9 \%$ more than the maximum floor rigidity of model 1 and the maximum floor rigidity of model 3 is similar to the maximum floor rigidity of model 1 .

(3)The floor displacement, the storey drifts, the floor shear and the floor rigidity of models in Y direction are shown in Figure 3. The maximum values of them are shown in Table 5.

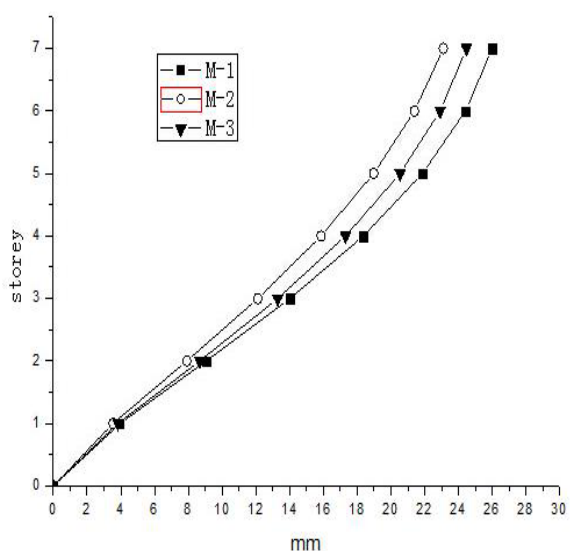

(a) Floor displacement curve

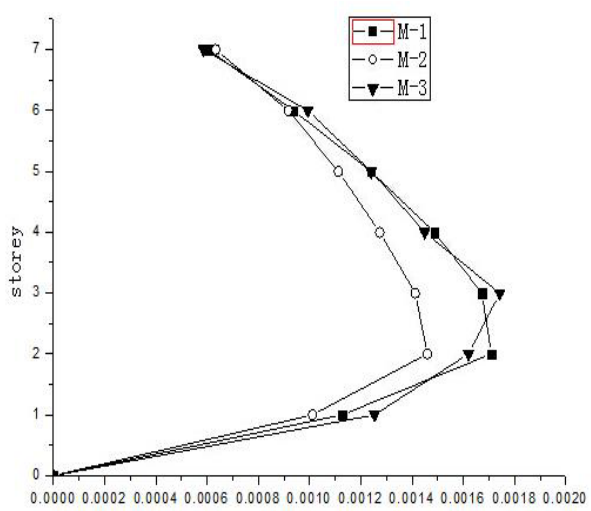

(b)Storey drift curve

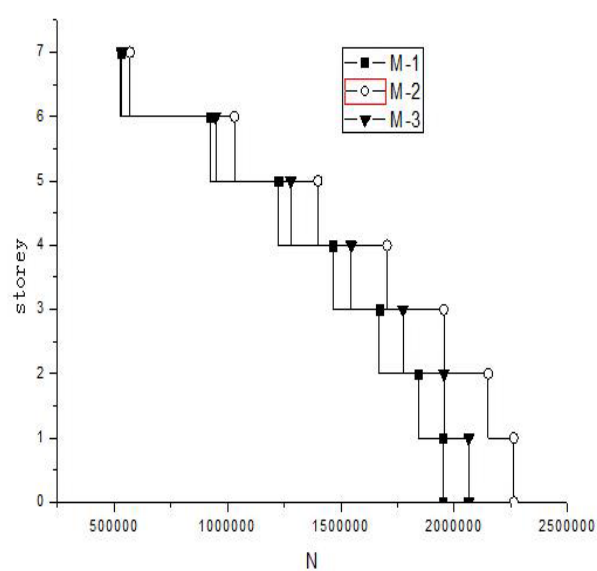

(c)Floor shear curve 
ICETA 2015

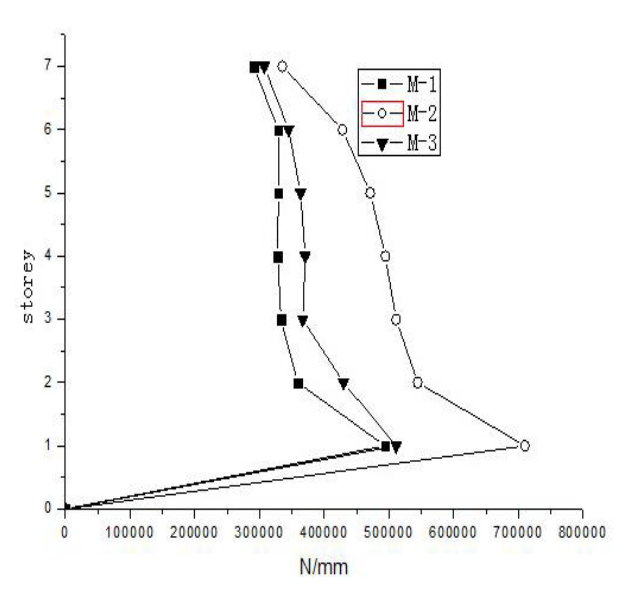

(d) Floor rigidity curve

Figure 3. Storey displacement, storey drifts, storey force and storey stiffness of models in Y-direction

Table 5. Maximum of storey response based on spectrum-case of model (Y-direction)

\begin{tabular}{lllll}
\hline Model & $\begin{array}{l}\text { Floor displace- } \\
\text { ment }(\mathrm{mm})\end{array}$ & $\begin{array}{l}\text { Storey } \\
\text { drifts }\end{array}$ & $\begin{array}{l}\text { Floor } \\
\text { shear }(\mathrm{kn})\end{array}$ & $\begin{array}{l}\text { Floor rigid- } \\
\text { ity }(\mathrm{kn} / \mathrm{mm})\end{array}$ \\
\hline $\mathrm{M}-1$ & 25.9957 & $1 / 585$ & 1949 & 494 \\
$\mathrm{M}-2$ & 24.5631 & $1 / 621$ & 2090 & 577.6 \\
$\mathrm{M}-3$ & 25.0471 & $1 / 603$ & 2021 & 522.7 \\
\hline
\end{tabular}

Figure 3 and Table 5 show that:1) The floor displacement of model 1 is less than the floor displacement of model 2; the floor displacement of model 3 is between the floor displacement model 1 and model 2.2) The max storey drifts of the model 1 and model 2 are at the second storey but the maximum storey drifts of the model 3 is at the third storey; the maximum storey drifts of model 2 is $14.56 \%$ less than the maximum storey drifts of model 1 ; the maximum storey drifts of model 3 is similar to the maximum storey drifts of model 1.3) The maximum floor shear of model 2 is $16.1 \%$ more than the maximum floor shear of model 1 ; the maximum floor shear of model 3 is $5.9 \%$ more than the maximum floor shear of model 1.4) The maximum floor rigidity of model 2 is $43.76 \%$ more than the maximum floor rigidity of model 1 and the maximum floor rigidity of model 3 is $3.4 \%$ more than the maximum floor rigidity of model 1 .

(4)The maximum shear of staircase frame columns is shown in table

Table 6. Maximum shear of staircase frame column based on response spectrum method

\begin{tabular}{llll}
\hline Model & M-1 & M-2 & M-3 \\
Shear force (KN) & 130.07 & 355.07 & 209.00 \\
\hline
\end{tabular}

It is shown in Table 6 that the maximum shear of staircase frame column in model 2 is nearly 3 times than that of model 1 and illustrates that adding the stairs makes the maximum shear of staircase frame column in the earthquake more easier to greatly increase and damage; the maximum staircase column shear of model M-3 is reduced by $41 \%$ than that of model $\mathrm{M}-2$, which means setting the isolation bearings make the internal force of frame column of the staircase be greatly reduced, thus it can avoid the staircase frame column's failure.

In a conclusion: 1) Setting the isolation bearings can effectively reduce the structural torsion caused by the stairs and prolong the structural vibration period. 2) Setting stairs has influence both on X-direction and $\mathrm{Y}$-direction and the influence on the Y-direction that parallels with stairs is more significant. 3) Setting stairs makes the floor rigidity increase significantly, while the floor displacement and the storey drifts decrease. Influence of stairs on structure is decreased obviously after setting the rubber isolation bearings.4) Setting the rubber isolation bearing makes the frame column shear forces which is caused by the arrangement of the stairs greatly reduced and effectively prevent the premature failure.

\section{CONCLUSIONS}

(1) Setting stairs changes the center of rigidity of the structure which influences on the torsion effect of structure. At the same time, it makes the lateral stiffness of the structure and the internal force of frame columns of staircase increased so that the staircase becomes a vulnerable part. The stairs which have mainly influence on the Y-direction are paralleled with stairs and cause a bridging effect along this direction.

(2) Setting the rubber isolation bearing reduces the effect of the stairs on the structure and the internal force of frame column in the staircase was significantly reduced during an earthquake. It can avoid early damage of staircase frame columns and make the seismic response of the structure similar to that not including stairs.

(3) In the traditional design method, the staircase components are often neglected, which may lead to the whole structure and the staircase damaged seriously during an earthquake. Therefore, the rubber isolation bearing should be set in the stairs to make the calculation model similar to the actual engineering.

\section{REFERENCES}

[1] Hongjun Dai \& Kai Qi. 2011. Analysis on seismic--response of reinforced concrete frame structure with different--thickness staircase. Journal of Fuzhou University (Natural Science Edition).

[2] Yanmei Jing, Xinpei Zhang \& Zhipeng Tina. 2012. Elastoplastic response analysis of frame with slab stairs under severe earthquake. World Earthquake Engineering.

[3] Wei Wang, Jianyang Xue, Daming Luo \& Xianwei Zhou. 2011. Analysis of the damage to building stairs in 


\section{MATEC Web of Conferences}

2008 Wenchuan earthquake. Journal of Earthquake Engineering and Engineering Vibration.

[4] Jun Zhao, Pengcheng Hou \& Min Liu. 2014. Shaking table test on structural model of concrete frame-staircase with sliding supports. Journal of Building Structures.

[5] Xiuchang Huang, Yong Chen, Hongxing Hua, Xingtian Liu \& Zhiyi Zhang. 2015. Shock isolation performance of a nonlinear isolator using Euler buckled beam as negative stiffness corrector: Theoretical and experimental study. Journal of Sound and Vibration.

[6] N. Chandra Shekhar, H. Hatwal \& A. Mallik. 1998 Response of non-linear dissipative shock isolators. Journal of Sound and Vibration.

[7] B. Tang M \& Brennan. 2014. On the shock performance of a nonlinear vibration isolator with high-static-lowdynamic-stiffness. International Journal of Mechanical Sciences.

[8] Cancellara Donato \& Pasquino Mario. 2010. Base isolated building with hybrid base isolation system (HDRB \& FS in parallel): Linear vs. Nonlinear dynamic analysis Ingegneria Sismica. 